\title{
Raman Studies of ZnO Products Synthesized by Solution Based Methods
}

\author{
D. GÜltekin*, H. AkBulut \\ Sakarya University, Metallurgical and Materials Engineering Dept., 54187, Sakarya, Turkey
}

\begin{abstract}
In this study, nanostructured $\mathrm{ZnO}$ thin film coatings produced by sol-gel method have been examined and characterized. $\mathrm{ZnO}$ thin film coatings synthesized by the preparation of $\mathrm{ZnO}$ sols in the liquid phase from homogeneous solutions with precursor of zinc acetate dihydrate $\left(\mathrm{Zn}\left(\mathrm{CH}_{3} \mathrm{COO}\right)_{2} \cdot 2 \mathrm{H}_{2} \mathrm{O}\right)$. Ethanol $\left(\mathrm{C}_{2} \mathrm{H}_{5} \mathrm{OH}\right)$ has been used as a solvent material and monoethanolamine (MEA) has been used as a complexing agent. The final solutions have $0.1,0.3,0.5,0.7$ and 1 molar concentrations. General morphologies and detailed structural characterizations have been obtained by using scanning electron microscope (SEM). Qualitative analyses of the synthesized coatings were performed using X-ray diffraction (XRD) and Raman spectroscopy. The Raman spectroscopy studies of precursor, solution and final products were carried out to investigate transformation of the chemical compounds from the initial material to the final coating.
\end{abstract}

DOI: 10.12693/APhysPolA.129.803

PACS/topics: 78.30.Fs, 81.07.Bc, 81.07.-b, 81.20.Fw

\section{Introduction}

Zinc oxide with its unique physical and chemical properties, such as high chemical stability, high electrochemical coupling coefficient, broad range of radiation absorption and high photostability, is a multifunctional and important semiconductor which has a range of applications in electronics and electrotechnology [1]. $\mathrm{ZnO}$ is a wide band gap $(3.37 \mathrm{eV})$ semiconductor and has a large exciton binding energy $(60 \mathrm{meV})[1,2]$, low resistivity and high transparency in the visible range and high light trapping characteristics [3]. As a result, zinc oxide can be used in photoelectronic and electronic equipment, in devices emitting surface acoustic waves, in field emitters, in sensors, in UV lasers, and in solar cells [1]. Nanostructured $\mathrm{ZnO}$ has been synthesized via a wide range of techniques. In particular, the sol-gel method is much more attractive than other methods because of low temperature processing conditions, easy composition control and homogeneity, easy fabrication of thin films with large area and low cost [4].

In this work, we aimed to produce and characterize $\mathrm{ZnO}$ thin film coatings. General morphologies and detailed structural characterizations were obtained by using scanning electron microscope, X-ray diffractometer and Raman spectroscopy. Raman spectroscopy is a nondestructive characterization method of choice for many recent studies of the vibrational properties of $\mathrm{ZnO}$ nanostructures [5].

\section{Materials and method}

Several zinc precursors have been used: nitrate, chloride, perchlorate, acetylacetonate and alkoxides such as

*corresponding author; e-mail: dkurt@sakarya.edu.tr ethoxide and propoxide, but the most often used is the acetate dihydrate. Because of their low cost, facility of use, and commercial availability, metal salts are interesting as precursors and could be more appropriate for large-scale applications [6]. In our work, $\mathrm{ZnO}$ thin film coatings were synthesized by the preparation of $\mathrm{ZnO}$ sols in the liquid phase from homogeneous solutions with precursor of zinc acetate dihydrate $\left(\mathrm{Zn}\left(\mathrm{CH}_{3} \mathrm{COO}\right)_{2} \cdot 2 \mathrm{H}_{2} \mathrm{O}\right)$. Ethanol $\left(\mathrm{C}_{2} \mathrm{H}_{5} \mathrm{OH}\right)$, was used as solvent. An appropriate amount of precursor was dissolved in ethanol to estimate solutions with different molar ratio. Generally, sol-gel $\mathrm{ZnO}$ is deposited from a zinc precursor dissolved in an alcohol with controlled water or an additive acting as a chelating agent [7]. Monoethanolamine (MEA) was added to solutions, because the hydrated zinc salts (acetate, nitrate, perchlorate) were dissolved in ethanol in the presence of monoethanolamine (MEA), which acts at the same time as a base and a complexing agent [6]. In this study, MEA was added to solutions until homogenous and transparent solutions were obtained. Then solutions have been stirred for $1 \mathrm{~h}$ to form a clear, stable and homogeneous sols at $60^{\circ} \mathrm{C}$. The final solutions had $0.1,0.3,0.5,0.7$ and 1 molar concentrations. Thin film deposition was carried out by dip coating method on Fluorine-doped tin oxide-coated glass substrates (FTO substrates; Solaronix; sheet resistance of $7 \mathrm{Ohm} / \mathrm{sq}$ ) for five times. After each coating process, the substrates were dried at $100^{\circ} \mathrm{C}$ for $20 \mathrm{~min}$. The produced thin films were heat treated in a furnace at $400^{\circ} \mathrm{C}$.

Ivanova et al. [8], have reported in their work that the high temperature annealing leads to a decrease of the transmittance in the visible range. The $\mathrm{ZnO}$ film treated at $400{ }^{\circ} \mathrm{C}$ shows transparency of $91 \%$ at the wavelength of $550 \mathrm{~nm}$ and in the same time, the films annealed at 500 and $600{ }^{\circ} \mathrm{C}$ reveal transmittance values of 87 and $80 \%$ $(\lambda=550 \mathrm{~nm})$, respectively [8]. A heat treatment temperature of $400^{\circ} \mathrm{C}$ is sufficient for the complete evaporation of organics and for initiation of the process of formation 
and crystallization of the $\mathrm{ZnO}$ film [9]. Detailed structural characterizations of the $\mathrm{ZnO}$ films were obtained using (SEM) and XRD was used to determine preferred crystal orientation of the thin films.

\section{Results and discussion}

The Raman spectroscopy of bulk $\mathrm{Zn}\left(\mathrm{CH}_{3} \mathrm{COO}\right)_{2} \cdot\left(\mathrm{H}_{2} \mathrm{O}\right)_{2}$ has been applied to examine the chemical contents evolution from the solution to the film. Figure 1 shows the Raman spectra of bulk zinc acetate dihydrate and zinc acetate dihydrate dissolved in ethanol with only 0.5 molar ratio, for brevity. Similar to the results from the literature, the peaks at $882 \mathrm{~cm}^{-1}, 1047 \mathrm{~cm}^{-1}$ and $1093 \mathrm{~cm}^{-1}$ correspond to ethanol [7]. The mode at $434 \mathrm{~cm}^{-1}$ in the dihydrate has been assigned to the $\mathrm{Zn}-\mathrm{O}$ bond. When the zinc acetate is dissolved in the ethanol, the $E_{2}$ mode shifts from $413 \mathrm{~cm}^{-1}$ to $434 \mathrm{~cm}^{-1}$ in the acetate solution, this is attributed to be due to the intermolecular stress. These bonds probably would initiate crystallization process during the films heat treatment. The mode observed at $928 \mathrm{~cm}^{-1}$ is attributed to be the A1 mode corresponding to the bond $\mathrm{C}-\mathrm{C}$ vibration, present in the radical $\left(\mathrm{CH}_{3} \mathrm{COO}^{-}\right)$of the zinc acetate dihydrate [7].

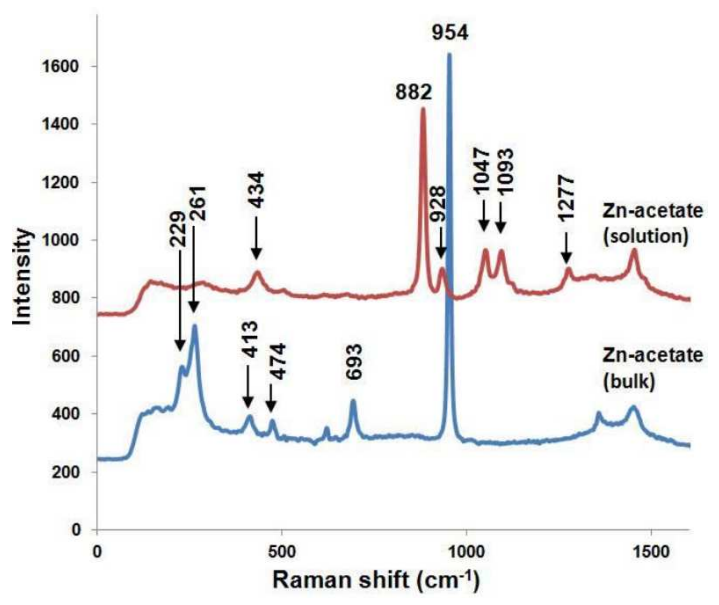

Fig. 1. Raman spectra of both bulk zinc acetate dihydrate and dissolved zinc acetate dihydrate in ethanol.

For wurtzite $\mathrm{ZnO}$ (space group $\mathrm{P} 6_{3} m c$ ) group theory predicts the existence of the following optic modes: $\Gamma_{\text {opt }}=\mathrm{A}_{1}+\mathrm{E}_{1}+2 \mathrm{E}_{2}+2 \mathrm{~B}_{1}$, where the $\mathrm{B}_{1}$ modes are silent, $\mathrm{A}_{1}$ and $\mathrm{E}_{1}$ are polar modes, both Raman and infrared active, while the $\mathrm{E}_{2}$ modes ( $\mathrm{E}_{2}^{\text {low }}$ and $\mathrm{E}_{2}^{\text {high }}$ ) are nonpolar and Raman active only $[5,7,10] . \mathrm{E}_{2}^{\text {high }}$ is associated with oxygen atoms and $\mathrm{E}_{2}^{\text {low }}$ is associated with $\mathrm{Zn}$ sublattice [11]. In addition, $\mathrm{A}_{1}$ and $\mathrm{E}_{1}$ are infrared active, and therefore they split into longitudinal and transverse optical component (LO and TO). The mode assignment at ambient conditions is well established in the literature [7]. Figure 2 shows Raman spectra of the $\mathrm{ZnO}$ thin films, and also FTO substrate. In the literature, $\mathrm{E}_{2}$ vibration mode at $440 \mathrm{~cm}^{-1}$ is a characteristic of the wurtzite phase.

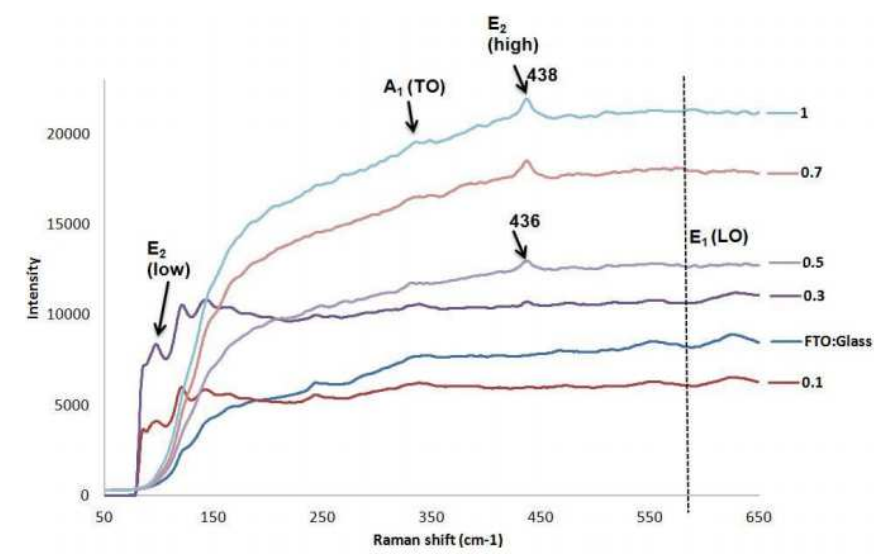

Fig. 2. Raman spectra of $\mathrm{ZnO}$ thin film coatings and FTO substrate.

The first-order Raman scattering from the $\mathrm{ZnO}$ vibrational modes are dominated by two peaks at about 99 and $440 \mathrm{~cm}^{-1}$, which can be assigned to the $\mathrm{E}_{2}^{\text {low }}$ and $\mathrm{E}_{2}^{\text {high }}$ optical phonons of the $\mathrm{ZnO}$ crystal, respectively [10]. In the $\mathrm{ZnO}$ thin film prepared with 0.7 and $1 \mathrm{M}$ solutions, the $\mathrm{E}_{2}^{\text {high }}$ mode at $438 \mathrm{~cm}^{-1}$ is seen. In the $\mathrm{ZnO}$ films with $0.5 \mathrm{M}$ solution the $\mathrm{E}_{2}^{\text {high }}$ mode at $438 \mathrm{~cm}^{-1}$ shifts towards $436 \mathrm{~cm}^{-1}$. In $0.3 \mathrm{M}$, the $\mathrm{E}_{2}^{\text {high }}$ mode has very low intensity while in $0.1 \mathrm{M}$ thin film, the spectrum has the $E_{2}^{\text {low }}$ instead of $E_{2}^{\text {high }}$. The peak $\mathrm{E}_{1}^{\text {low }}$ approximately positioned at $584 \mathrm{~cm}^{-1}$ is attributed to the formation of the defects, such as an absence of oxygen, interstitial $\mathrm{Zn}$, and the free carrier lack [7, 10]. No other peaks were observed at that point, or around.

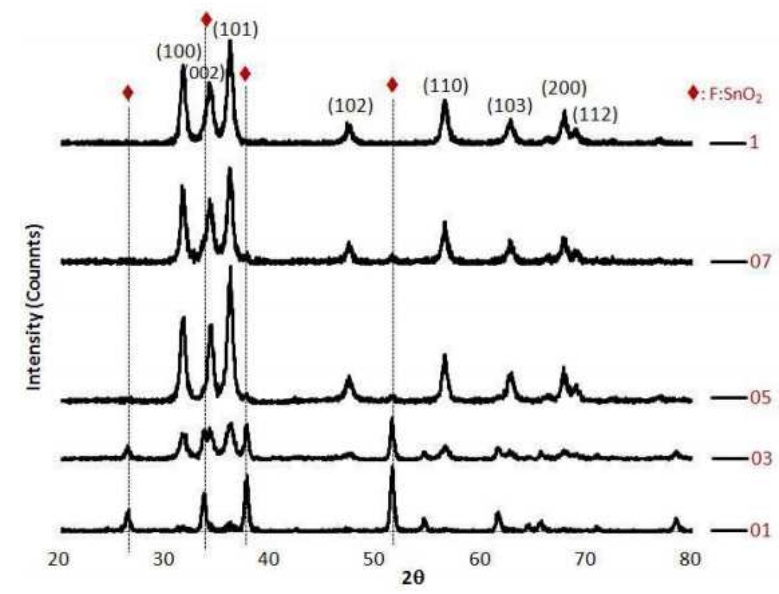

Fig. 3. XRD patterns of $\mathrm{ZnO}$ thin film coatings.

Figure 3 presents the X-ray diffraction patterns of synthesized $\mathrm{ZnO}$ thin film coatings. The peak positions in each product agree well with the reflections of $\mathrm{ZnO}$ with all peaks corresponding well to standard crystallographic data (ZnO: JCPDS 01-075-0576). As could be seen from the XRD patterns, all products have polycrystalline nature, randomly oriented. Peaks belonging to the (100), 
(002), (101) (102), (110) and (103) reflections were seen in $\mathrm{ZnO}$. The symbol represents the diffraction peaks originating from the FTO-coated glass substrate.

Furthermore, no other peak related to impurities were detected in the spectrum, which further confirms that the synthesized products are of high purity. There have been changes in orientation and peaks intensities for different solution concentration. The preferred orientations corresponding to (100) and (101) planes were observed for all coatings, while the intensities of peaks increased with the increasing sol concentration. Znaidi [6] has reported, a different preferential orientation of the $\mathrm{ZnO}$ films, which seems to be related with the solution or sol concentration, and the effective coverage of the substrate surface, rather than to the nature of the precursor. The same author [6] stated that all production parameters play a role in the film orientation and unfortunately, no clear correlation does exist between each of these parameters and such crystallographic orientation.

Figure 4 represents the SEM images of $\mathrm{ZnO}$ thin films. It was observed that thin films synthesized from low concentration solutions have a wrinkled structure. Pattern formation in thin films caused by the relaxation of stress is a phenomenon that is frequently encountered both in nature and in technology. In sol-gel-derived thin films, compressive stress due to the difference in the thermal expansion coefficients between the film and substrate is generated during the drying process, which leads to bending of the gelated thin film [12].

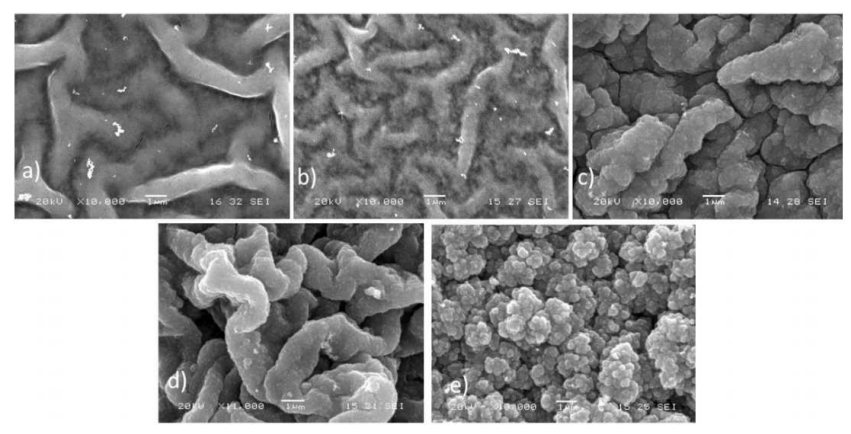

Fig. 4. SEM images of $\mathrm{ZnO}$ thin film coatings.

With the increasing molar ratio, grains become merged and the morphology of the film becomes denser. The rate of particle growth is governed by the concentration of precursors or dissolved species and their reactivity, which depends on the number of particle surface atoms, and the solution composition. As the concentration increases, the amount of solute increases in the sol and therefore the electrostatic interaction between the solute particles becomes larger, thereby increasing the probability of more solute to be gathered together, forming a grain. Thus as the concentration increases, grain size also increases [6].

\section{Conclusions}

$\mathrm{ZnO}$ thin films have been produced by sol-gel method. General morphologies and structural characterizations were carried out by characterization techniques. Raman analysis of precursor material, Zn-based solution and final $\mathrm{ZnO}$ thin film coatings was carried out to investigate transformation of the chemical compounds from the initial material to the final coating. The characteristic wurtzite mode $\mathrm{E}_{2}^{\text {high }}$ was observed in both solution and in thin film coatings. XRD patterns of $\mathrm{ZnO}$ thin film coatings have agreed well with the reflections of $\mathrm{ZnO}$, with all peaks corresponding to standard crystallographic data. Products have randomly oriented polycrystalline nature. The preferred orientation corresponding to (100), (002) and (101) planes were observed for all coatings. SEM results showed that thin films with low molarity have wrinkled structure due to compressive stress between the film and the substrate, generated during the drying process. With the increase of the molar ratio, grains are merged and morphology of the films becomes denser.

\section{References}

[1] A. Kołodziejczak-Radzimska, T. Jesionowski, Materials 7, 2833 (2014).

[2] S. Ilican, Y. Caglar, M. Caglar, F. Yakuphanoglu, Appl. Surf. Sci. 255, 2353 (2008).

[3] Y. Caglar, S. Ilican, M. Caglar, F. Yakuphanoglu, Spectrochimica Acta Part A 67, 1113 (2007).

[4] M.C. Kao, H.Z. Chen, S.L. Young, Appl. Phys. A 98, 595 (2010).

[5] K.A. Alim, V.A. Fonoberov, M. Shamsa, A.A. Balandin, J. Appl. Phys. 97, 124313 (2005).

[6] L. Znaidi, Mater. Sci. Eng. B 174, 18 (2010).

[7] S.B. Yahia, L. Znaidi, A. Kanaev, J.P. Petitet, Spectrochim. Acta Part A 71, 1234 (2008).

[8] T. Ivanova, A. Harizanova, T. Koutzarova, B. Vertruyen, Mater. Letters 64, 1147 (2010).

[9] P. Sagar, P.K. Shishodia, R.M. Mehra, Appl. Surf. Sci. 253, 5419 (2007).

[10] D.L. Golic, G. Brankovic, M.P. Nesic, K. Vojisavljevic, A. Recnik, N. Daneu, S. Bernik, M. Scepanovic, D. Poleti, Z. Brankovic, Nanotechnology 22, 395603 (2011).

[11] I. Calizo, K.A. Alim, V.A. Fonoberov, S. Krishnakumar, M. Shamsa, A.A. Balandin, R. Kurtz, Quantum Dots, Particles, and Nanoclusters IV, Proc. of SPIE, Vol. 6481, 64810N-1, (2007).

[12] S.J. Kwon, J-H. Park, J-G. Park, Phys. Rev. E 71, 011604 (2005). 